\title{
Prevalence of Accessory Bones and Tarsal Coalitions Based on Radiographic Findings in a Healthy, Asymptomatic Population
}

\author{
Jae Hee Lee, MD, Min Gyu Kyung, MD, Yun Jae Cho, MD, Tae Won Go, MD, Dong Yeon Lee, MD
}

Department of Orthopedic Surgery, Seoul National University Hospital, Seoul, Korea

Background: Accessory bones and tarsal coalitions are the most common developmental variations of the foot and ankle. However, their clinical implications are not well understood because there is no established prevalence data in the normal population and the reported prevalence varies widely. Therefore, we aimed to investigate the incidence of accessory ossicles and tarsal coalitions in a healthy, asymptomatic Korean population.

Methods: A total of 448 healthy, asymptomatic participants (224 men and 224 women; 896 feet) were enrolled and stratified by age and sex. To investigate the presence of accessory bones and tarsal coalitions in the foot and ankle, we obtained the weightbearing standing radiographs (anteroposterior and lateral views) from each participant.

Results: Accessory ossicles were found in $49.2 \%$ of the healthy, asymptomatic Korean adults. The prevalence of accessory bones in adults was the highest with $34 \%$ for the accessory navicular, $5.8 \%$ for the os trigonum, $3.9 \%$ for the os peroneum, and $1.7 \%$ for the os subfibulare. The prevalence of tarsal coalitions in adults was $0.4 \%$ and that of symphalangism was $16 \%$ for the fourth toe and $80.6 \%$ for the fifth toe. The frequency of the accessory navicular and fifth toe symphalangism was significantly higher in women. Most of the accessory navicular and fourth and fifth toe symphalangism were bilateral, whereas the os subfibulare was mostly unilateral.

Conclusions: The prevalence of accessory bones and tarsal coalitions in the healthy, asymptomatic Korean population showed some variation according to age and sex.

Keywords: Os naviculare, Tarsal coalition, Foot bone

Accessory bones and tarsal coalitions are the most common developmental variations in the foot and ankle. Accessory bones are usually derived from unfused primary or secondary ossification centers and may exist adjacent to the main bone where they are separated. ${ }^{1)}$ Tarsal coalitions are abnormal connections of two or more tarsal bones and are regarded as the results of impaired mesenchymal separation of the tarsal bones. ${ }^{2,3)}$ They can be divided into os-

Received August 1, 2019; Accepted December 17, 2019

Correspondence to: Yun Jae Cho, MD

Department of Orthopedic Surgery, Seoul National University Hospital,

101 Daehak-ro, Jongno-gu, Seoul 03080, Korea

Tel: +82-2-2072-1863, Fax: +82-2-764-2718

E-mail: ckoko0@naver.com seous (synostosis), fibrous (syndesmosis), or cartilaginous (synchondrosis) connections. ${ }^{4)}$ Although accessory bones and tarsal coalitions may be present at birth, individuals with accessory bones or tarsal coalitions can be asymptomatic; therefore, these might not be noticed until an incidental radiographic examination reveals their presence. However, some conditions, such as talocalcaneal coalition, calcaneonavicular coalition, os subfibulare, os trigonum, and os naviculare, can cause pain around the foot and ankle and require clinical interventions. Symphalangism of the toe, also known as the biphalangeal toe, is an uncommon condition characterized by fusion of interphalangeal joints. Toe symphalangism has been evaluated in several studies and has been shown as the most common variant resulting from incomplete segmentation rather than pha- 
Lee et al. Accessory Bones and Tarsal Coalitions in Radiographic Findings

Clinics in Orthopedic Surgery • Vol. 12, No. 2, $2020 \bullet$ www.ecios.org

langeal fusion. ${ }^{5-7)}$

The clinical importance of accessory bones is usually emphasized in differential diagnosis from acute trauma or fracture. ${ }^{8-10)}$ Although several studies have reported the prevalence of accessory bones and tarsal coalitions, the number of detected bones and range of prevalence vary widely in literature. ${ }^{4,6,10-12)}$ This may be due to differences in the sample size, age, sex, and race of patients, and measurement method. Furthermore, results from previous studies are not representative of the normal population because the participants were patients who visited hospitals for discomfort around the foot and ankle even though it was not directly related with the accessory bones. ${ }^{6,711,12)}$

To the best of our knowledge, there has been no population-based study that has identified the difference in the prevalence of accessary bones and tarsal coalitions according to age and sex. Therefore, this study aimed to investigate the prevalence of accessory bones and tarsal coalitions in a healthy, asymptomatic population and analyze the differences in incidence according to age and sex.

\section{METHODS}

We conducted this study in compliance with the principles of the Declaration of Helsinki. This study was reviewed and approved by the Institutional Review Board of Seoul National University Hospital (IRB No. H-1809-015-969l) and the need for informed consent was waived.

\section{Study Population}

A total of 448 healthy, asymptomatic participants (224 men and 224 women; 896 feet) were recruited from the local area between January 2011 and November 2018 to obtain reference data for a normal gait analysis. Simple X-ray examinations were conducted to detect a bony deformity in each participant. Using the X-ray data, we analyzed the respective prevalence of accessory bones and tarsal coalitions. The participants were divided into six subgroups according to age and sex as follows: NYM, normal young male adult; NOM, normal old male adult; NYF, normal young female adult; NOF, normal old female adult; NPM,

Table 1. Demographic Data of Participating Subjects

\begin{tabular}{|c|c|c|c|c|c|}
\hline \multirow{2}{*}{ Subject } & \multicolumn{2}{|c|}{ Male } & \multicolumn{2}{|c|}{ Female } & \multirow{2}{*}{ Total } \\
\hline & no. & Mean (yr, range) & no. & Mean (yr, range) & \\
\hline Child & 88 & $10.4(7-17)$ & 94 & $10.0(7-17)$ & 182 \\
\hline Young adult & 87 & $26.4(20-35)$ & 80 & $25.1(18-35)$ & 167 \\
\hline Old adult & 49 & $64.6(60-69)$ & 50 & $64.6(60-69)$ & 99 \\
\hline Total & 224 & - & 224 & - & 448 \\
\hline
\end{tabular}

Table 2. The Prevalence of Accessory Bones, Tarsal Coalitions, and Symphalangisms in Normal Adult Population According to Age and Sex

\begin{tabular}{|c|c|c|c|c|}
\hline \multirow{2}{*}{ Variable } & \multicolumn{2}{|c|}{ Male ( $n=136,272$ feet) } & \multicolumn{2}{|c|}{ Female ( $n=130,260$ feet) } \\
\hline & Young & Old & Young & Old \\
\hline Number/foot & $87 / 174$ & 49/98 & $80 / 160$ & $50 / 100$ \\
\hline Accessory navicular & $50(28.7)$ & $29(29.6)$ & $60(37.5)$ & $42(42.0)$ \\
\hline Os subfibulare & $7(4.0)$ & 0 & $2(1.25)$ & 0 \\
\hline Os peroneum & $3(1.7)$ & $7(7.1)$ & $7(4.4)$ & $4(4.0)$ \\
\hline Os trigonum & $15(8.6)$ & $5(5.1)$ & $7(4.4)$ & $4(4.0)$ \\
\hline Tarsal coalition & $2(1.15)$ & 0 & 0 & 0 \\
\hline 4th symphalangism & $30(17.2)$ & $7(7.1)$ & $36(22.5)$ & $12(12.0)$ \\
\hline 5th symphalangism & $135(77.6)$ & $71(72.5)$ & $130(81.3)$ & $93(93.0)$ \\
\hline
\end{tabular}

Values are presented as number (\%). 
Lee et al. Accessory Bones and Tarsal Coalitions in Radiographic Findings

Clinics in Orthopedic Surgery • Vol. 12, No. 2, $2020 \bullet$ www.ecios.org

normal pediatric male; and NPF, normal pediatric female. Demographic data are presented in Table 1. Exclusion criteria were a symptomatic foot (pain or discomfort), trauma or surgical history involving the lower extremities, and diagnosis of foot and ankle disease.

\section{Radiographic Evaluation}

We obtained the weight-bearing standing radiographs (anteroposterior and lateral views) from each participant. After excluding abnormal bony alignments, such as flatfoot or cavus foot, per previously reported protocol, ${ }^{13}$ ) we analyzed all accessory bones and tarsal coalitions in the foot and ankle. Radiographs were retrospectively reviewed by two orthopedic residents (MGK, TWG) and confirmed by a foot-and-ankle specialist (JHL).

\section{Statistical Analysis}

All statistical analyses were performed by using IBM SPSS ver. 24.0 (IBM Corp., Armonk, NY, USA). Radiographic examinations were performed to evaluate the prevalence of accessory ossicles and tarsal coalitions. Fisher exact test was used to determine the statistical significance. A $p<0.05$ was considered statistically significant.

\section{RESULTS}

Accessory ossicles were present in $131(49.2 \%)$ healthy, asymptomatic Korean adults $(\mathrm{n}=266): 44(50 \%)$ in NYM ( $\mathrm{n}$ $=87), 23(46.9 \%)$ in NOM ( $\mathrm{n}=49), 42(52.5 \%)$ in NYF ( $\mathrm{n}$ $=80)$, and $26(52 \%)$ in NOF $(\mathrm{n}=50)$. In the pediatric male

\begin{tabular}{|c|c|c|c|}
\hline Variable & $\begin{array}{c}\text { Child } \\
\left(\mathrm{n}=112,224 \text { feet* }^{*}\right. \\
\left.\mathrm{n}=18,364 \text { feet }^{\dagger}\right)\end{array}$ & $\begin{array}{c}\text { Adult } \\
\text { ( } n=266 \\
532 \text { feet) }\end{array}$ & $p$-value \\
\hline Accessory navicular & $49(21.88)^{*}$ & $18(34.0)$ & $<0.01$ \\
\hline Os subfibulare & $1(0.47)^{*}$ & $9(1.7)$ & 0.30 \\
\hline Os peroneum & $0^{*}$ & $21(3.9)$ & $<0.01$ \\
\hline Os trigonum & $9(4.02)^{*}$ & $31(5.8)$ & 0.15 \\
\hline Tarsal coalition & $0^{*}$ & $2(0.38)$ & 1.00 \\
\hline 4th symphalangism & $13(3.57)^{\dagger}$ & 82 (15.98) & $<0.01$ \\
\hline 5th symphalangism & $113(31.04)^{\dagger}$ & 429 (80.6) & $<0.01$ \\
\hline
\end{tabular}

Values are presented as number (\%).

*Prevalence of accessory bones observed since the first occurrence (male: $10 \mathrm{yr}$, female: $8 \mathrm{yr})$. ${ }^{\dagger}$ Prevalence of symphalangism observed since the first occurrence (male: $7 \mathrm{yr}$, female: $7 \mathrm{yr}$ ). and female participants, accessory bones first appeared at the age of 10 years and 8 years, respectively. Of the total NPM aged 10 years or older $(n=44), 15(34.1 \%)$ had accessory bones, and of the total NPF aged 8 years or older ( $\mathrm{n}$ $=68), 17(25 \%)$ had accessory bones.

The prevalence of accessory bones in adults was the highest with $34 \%$ for the accessory navicular, $5.8 \%$ for the os trigonum, $3.9 \%$ for the os peroneum, and $1.7 \%$ for the os subfibulare. The prevalence of tarsal coalitions in adults was $0.4 \%$, and that of symphalangism was $16 \%$ for the fourth toe and $80.6 \%$ for the fifth toe (95\% confidence level, 75.18 to 86.02 ; sampling error, \pm 4.25$)$. However, only two cases of talocalcaneal coalition were observed, and the os calcaneus secondarius, os vesalianum, os intermetatarseum, and os supranaviculare were not observed in our study population.

The prevalence of accessory bones and tarsal coalitions was investigated according to age and sex (Table 2). The frequency of the accessory navicular and fifth toe symphalangism was statistically significantly higher in women than men ( $p=0.01$ and $p<0.01$, respectively). On comparison between children and adults, the prevalence of the accessory navicular, os peroneum, os trigonum, and symphalangism in the fourth and fifth toes was statistically significantly higher in adults than in children (Table 3). In most cases, the accessory navicular and symphalangism were observed bilaterally and the os subfibulare was observed unilaterally (Table 4).

\section{DISCUSSION}

In this study, we evaluated the prevalence of accessory

\begin{tabular}{|c|c|c|c|c|}
\hline \multirow{2}{*}{ Variable } & \multicolumn{2}{|c|}{ Child } & \multicolumn{2}{|c|}{ Adult } \\
\hline & Unilateral & Bilateral & Unilateral & Bilatera \\
\hline Accessory navicular & 25 & 75 & 23.2 & 76.8 \\
\hline Os subfibulare & 100 & 0 & 87.5 & 12.5 \\
\hline Os peroneum & - & - & 68.7 & 31.3 \\
\hline Os trigonum & 50 & 50 & 61.9 & 38.1 \\
\hline Tarsal coalition & - & - & 0 & 100 \\
\hline 4th symphalangism & 37.5 & 62.5 & 19.1 & 80.9 \\
\hline 5th symphalangism & 11.7 & 88.3 & 5 & 95 \\
\hline
\end{tabular}

Values are presented as percentage. 
Lee et al. Accessory Bones and Tarsal Coalitions in Radiographic Findings

Clinics in Orthopedic Surgery • Vol. 12, No. 2, $2020 \bullet$ www.ecios.org

bones and tarsal coalitions in a healthy, asymptomatic Korean population; some differences were observed in the incidence according to age and sex. Developmental variations in the foot and ankle, such as accessory bones, sesamoid bones, bipartitions, and coalitions, have already been reported. ${ }^{1,10,14,15)}$ Although accessory bones and tarsal coalitions might not generally cause symptoms, they are well known to cause pain and functional impairment in some patients. Moreover, some pathologic situations are also thought to be related with the presence of accessory ossicles and tarsal coalitions, such as the prehallux syndrome, posterior tibial tendon dysfunction, stenosing tenosynovitis of the flexor hallucis longus, and flatfoot. However, the clinical implications of accessory bones and tarsal coalitions cannot be determined because of the paucity of reliable data on the prevalence in normal populations.

The reported prevalence of the overall accessory ossicles in the foot and ankle is $18 \%-36.3 \%$ in the general population, ${ }^{10,15,16)}$ which was $46.9 \%-52.5 \%$ in this study depending on age and sex. The prevalence of the accessory navicular, also known as the os tibiale, os tibiale externum, and naviculare secundarium, was $4 \%-21 \%$ in previous studies. ${ }^{14,17,18)}$ This ossicle was found in $11.7 \%$ of Turkish population and $21.3 \%$ of Japanese population. ${ }^{10,19)}$ Koo et al. ${ }^{11)}$ reported that the incidence of the accessory navicular was $23 \%$ on conventional radiography, but $33 \%$ on digital tomosynthesis in a Korean population. The prevalence of the accessory navicular in the current study was $34 \%$, which is higher than that of the previous studies where the value widely varied depending on the race and measurement method.

The os peroneum is a sesamoid bone embedded in the peroneus longus tendon, adjacent to the calcaneocuboid joint. The prevalence of this ossicle was $9 \%$ in previous studies. ${ }^{14,18-20)}$ Miller ${ }^{17)}$ and Miller et al. ${ }^{21)}$ reported the incidence of the os peroneum was up to $26 \%$, and Coskun et al. ${ }^{10)}$ reported it to be $4.7 \%$. Koo et al. ${ }^{11)}$ reported the incidence of the os peroneum was $14 \%$ on conventional radiography, but $21 \%$ on digital tomosynthesis. However, the prevalence of this ossicle was only $3.9 \%$ in this study. The os peroneum is best evaluated in the oblique lateral view of the foot. ${ }^{14,17-19)}$ Therefore, it might have been underdiagnosed in our study because we only examined the anteroposterior and lateral views, not oblique views.

The os trigonum is connected to the lateral tubercle in the posterior process of the talus by a fibrocartilaginous synchondrosis. This ossicle is eventually related to posteromedial ankle pain. Its prevalence was $1 \%-25 \% .{ }^{14,18,22)}$ Koo et al. ${ }^{11)}$ reported the incidence of the os peroneum was $32 \%$ on conventional radiography, but $0.5 \%$ on digital tomosynthesis. However, the study population consisted of patients who visited the hospital for foot and ankle pain in the study, which might have resulted in the higher incidence. In the present study, the prevalence was only $5.8 \%$.

The os subfibulare is an ossicle under the tip of the distal fibula, with widely varying morphologic characteristics, from an oval to a chip shape. It was thought as an accessory ossicle caused by skeletal variation; however, a recent study proposed that it is rather a trauma-related accessory ossicle. $^{23)}$ Its prevalence is known as approximately $1 \%-2 \%{ }^{14,18,19,24)}$ In our study, the prevalence was $1.7 \%$.

The prevalence of the os calcaneus secondarius, os vesalianum, os supranaviculare, os intermetatarseum, and os subtibiale was $0.6 \%-7 \%, 0.1 \%, 1 \%, 1.2 \%-10 \%$, and $0.9 \%$, respectively, in previous studies. ${ }^{14,19)}$ However, these ossicles were not found in our study.

The tarsal coalition is an abnormal connection of two or more bones in the foot. In the previously reported literature, the incidence of tarsal coalitions was approximately $1 \%-6 \%$; however, the real incidence could be higher because they are often asymptomatic and undiagnosed. ${ }^{3,25)}$ Solomon et al. ${ }^{26)}$ showed in their 100 cadaver study that the prevalence of tarsal coalition was $13 \%$, whereas Nalaboff and Schweitzer ${ }^{27)}$ in their 574 magnetic resonance imaging (MRI)-based study, showed a prevalence of $11.5 \%$. In our study, the prevalence was $0.4 \%$, which could have been underestimated because only osseous coalitions can be detected in a simple radiographic assessment and our study population was composed of symptom-free healthy participants. Further studies would be necessary to determine the incidence and clinical implications of tarsal coalitions in healthy asymptomatic population.

Symphalangism is recognized as a normal variant resulting from incomplete segmentation of the distal phalanx. ${ }^{5)}$ Symphalangism in the fifth toe is characterized by a straight or slightly supinated toe (Fig. 1). Triphalangism is characterized by a more flexed and supinated toe, and the lateral side of the fifth toe easily rubs against the floor or shoes (Fig. 2). Therefore, it is often accompanied by corn or callus. Gallart et al. ${ }^{6}$ reported that the incidence of pathological fifth toe, such as a hammer toe and corn, was more common at the triphalangeal toe than at the biphalangeal toe because of the higher motility and deviated tendency of the triphalangeal fifth toe. In previous studies, the incidence of symphalangism in the fifth toe ranges from $35.5 \%$ to $80.4 \%$ according to race. ${ }^{28)}$ The prevalence in the fourth and fifth toes was $2.15 \%$ and $40.2 \%$, respectively, in a European population and $11.9 \%$ and $74.7 \%$, 
Lee et al. Accessory Bones and Tarsal Coalitions in Radiographic Findings

Clinics in Orthopedic Surgery • Vol. 12, No. 2, $2020 \bullet$ www.ecios.org
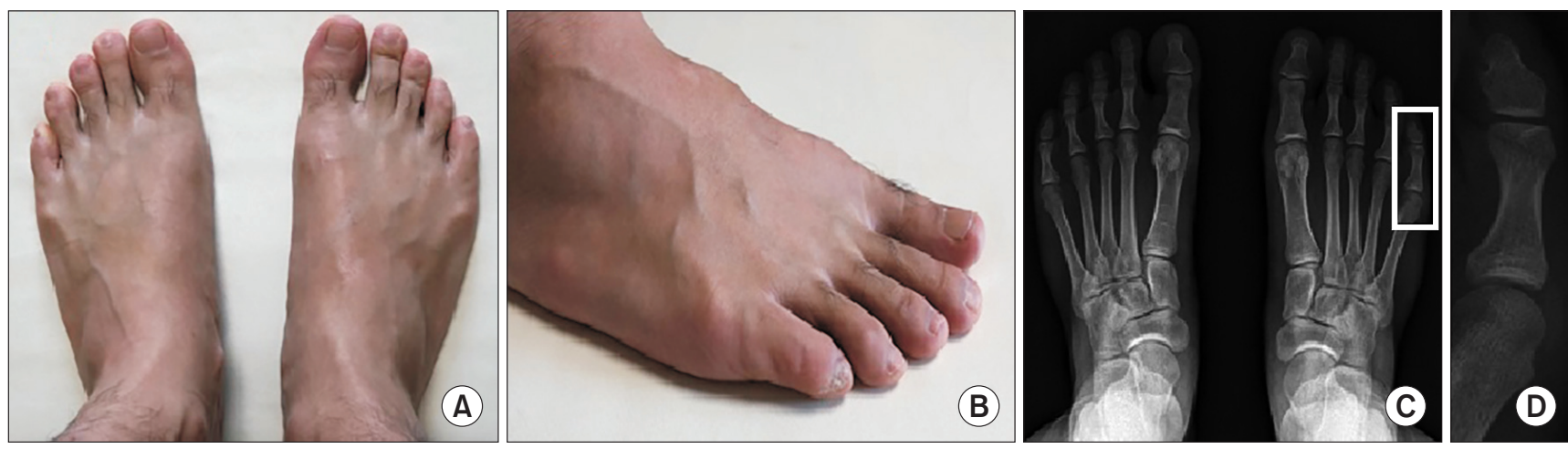

Fig. 1. Biphalangeal fifth toe (symphalangism). (A, B) Clinical photographs of the foot with biphalangeal fifth toe. The fifth toe appears straight. (C) Weight-bearing anteroposterior radiograph of the foot. (D) Anteroposterior radiograph of the fifth toe.
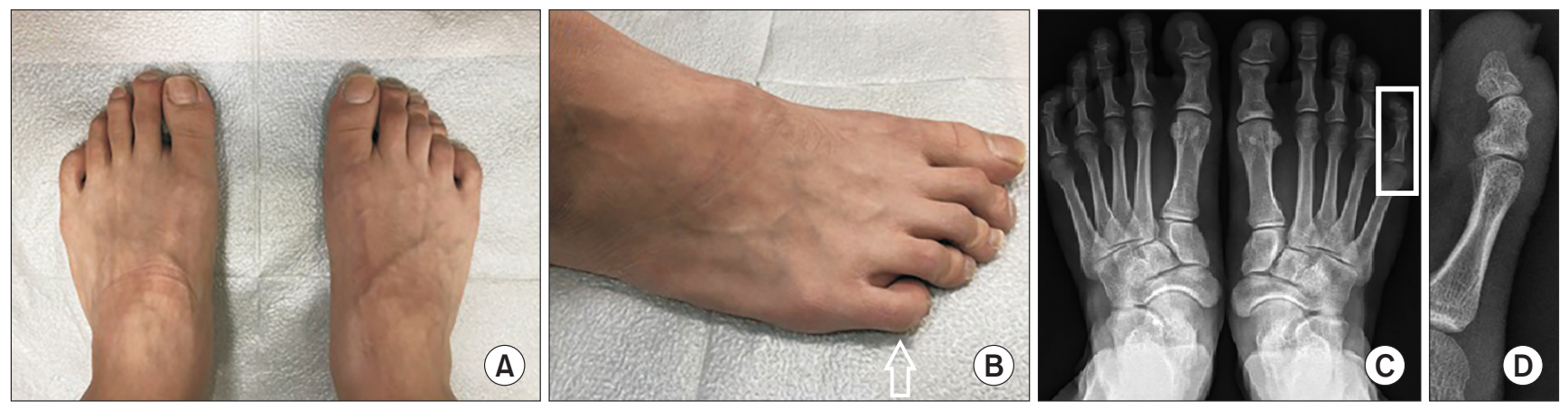

Fig. 2. Triphalangeal fifth toe. (A, B) Clinical photographs of the foot with triphalangeal fifth toe. The fifth toe is bent and supinated and has a hard corn on the lateral side of the middle phalanx (white arrow). (C) Weight-bearing anteroposterior radiograph of the foot. (D) Anteroposterior radiograph of the fifth toe.

respectively, in a Japanese population. ${ }^{7,29)}$ In the present study, the prevalence of fourth and fifth biphalangeal toes was $16 \%$ and $80.6 \%$, respectively.

The prevalence of accessory foot ossicles and tarsal coalitions widely varies in the literature and is different according to the sample size, measurement method, age, sex, and race. Moreover, the prevalence and characteristics of accessory bones and tarsal coalitions may differ between patient groups and asymptomatic healthy groups, between men and women, and among children, young adults, and older adults. Therefore, the significance of our study lies in the fact that it was conducted on healthy, asymptomatic participants and the difference was analyzed according to age and sex.

In our study, $49.2 \%$ of the healthy, asymptomatic population had one or more accessory ossicles in the foot and ankle. In addition, accessory naviculars were most commonly observed; they were present in $34 \%$ of the total study population. The prevalence of the fifth toe symphalangism was up to $80.6 \%$ in the normal population. The prevalence of accessory bones and tarsal coalitions dif- fered depending on sex, and the accessory navicular and symphalangism in the fifth toe were statistically significantly more common in women than men. Moreover, in most cases, the accessory navicular and symphalangism in the fourth and fifth toes were observed bilaterally, whereas the os subfibulare was mostly unilateral. The former was thought to be due to skeletal variation, but the latter was thought to be a result of trauma in a previous study by Lee et al. ${ }^{23)}$

This study has some limitations. First, the study subjects were asymptomatic, healthy subjects; thus, they did not represent the general population including the symptomatic and asymptomatic people, which may have resulted in selection bias. In fact, the prevalence of accessory bones and tarsal coalitions might be higher in the general population. Second, the number of samples was somewhat insufficient to be generalized. Third, because only simple X-ray images were reviewed, synchondrosis and syndesmosis types of tarsal coalitions were not detected. Moreover, we acknowledge accessory bones and tarsal coalitions might have been underdiagnosed because only 
Lee et al. Accessory Bones and Tarsal Coalitions in Radiographic Findings

Clinics in Orthopedic Surgery • Vol. 12, No. 2, $2020 \bullet$ www.ecios.org

simple anteroposterior and lateral views of the foot, not oblique views or computed tomography and MRI, were available for review, which is one of the limitations inherent to the retrospective design. Lastly, a problem with ethnic homogeneity was observed. In the current study, only a single ethnic race was studied; therefore, these results cannot be directly applied to other ethnicities.

This study is the first detailed report on the incidence of foot and ankle accessory ossicles and tarsal coalitions in a healthy Korean population. Based on the find- ings, symptom-related ossicles and their implications, such as the correlation between the accessory navicular and flatfoot and between os subfibulare and ankle impingement syndrome, should be evaluated further.

\section{CONFLICT OF INTEREST}

No potential conflict of interest relevant to this article was reported.

\section{REFERENCES}

1. Nwawka OK, Hayashi D, Diaz LE, et al. Sesamoids and accessory ossicles of the foot: anatomical variability and related pathology. Insights Imaging. 2013;4(5):581-93.

2. Upasani VV, Chambers RC, Mubarak SJ. Analysis of calcaneonavicular coalitions using multi-planar threedimensional computed tomography. J Child Orthop. 2008;2(4):301-7.

3. Zaw H, Calder JD. Tarsal coalitions. Foot Ankle Clin. 2010;15(2):349-64.

4. Klammer G, Espinosa N, Iselin LD. Coalitions of the tarsal bones. Foot Ankle Clin. 2018;23(3):435-49.

5. Le Minor JM. Biphalangeal and triphalangeal toes in the evolution of the human foot. Acta Anat (Basel). 1995;154(3): 236-41.

6. Gallart J, Gonzalez D, Valero J, Deus J, Serrano P, Lahoz M. Biphalangeal/triphalangeal fifth toe and impact in the pathology of the fifth ray. BMC Musculoskelet Disord. 2014; 15:295.

7. Ceynowa M, Rocławski M, Pankowski R, Mazurek T. The prevalence and ossification pattern of the biphalangeal and triphalangeal lateral toes. Surg Radiol Anat. 2018;40(9):1039-45.

8. Le Minor JM. Comparative anatomy and significance of the sesamoid bone of the peroneus longus muscle (os peroneum). J Anat. 1987;151:85-99.

9. Bizarro AH. On sesamoid and supernumerary bones of the limbs. J Anat. 1921;55(Pt 4):256-68.

10. Coskun N, Yuksel M, Cevener M, et al. Incidence of accessory ossicles and sesamoid bones in the feet: a radiographic study of the Turkish subjects. Surg Radiol Anat. 2009;31(1):19-24.

11. Koo BS, Song Y, Lee S, Sung YK, Sung IH, Jun JB. Prevalence and distribution of sesamoid bones and accessory ossicles of the foot as determined by digital tomosynthesis.
Clin Anat. 2017;30(8):1072-6.

12. Cilli F, Akcaoglu M. The incidence of accessory bones of the foot and their clinical significance. Acta Orthop Traumatol Turc. 2005;39(3):243-6.

13. Davids JR, Gibson TW, Pugh LI. Quantitative segmental analysis of weight-bearing radiographs of the foot and ankle for children: normal alignment. J Pediatr Orthop. 2005;25(6):769-76.

14. Sarrafian SK. Osteology. In: Kelikian AS, Sarrafian SK, eds. Sarrafian's anatomy of the foot and ankle: descriptive, topographic, functional. Philadelphia: Lippincott; 1993. 99-110.

15. Mellado JM, Ramos A, Salvado E, Camins A, Danus M, Sauri A. Accessory ossicles and sesamoid bones of the ankle and foot: imaging findings, clinical significance and differential diagnosis. Eur Radiol. 2003;13 Suppl 4:L164-77.

16. Coughlin MJ. Sesamoid and accessory bones of the foot. In: Coughlin MJ, Saltzman CL, eds. Mann's surgery of the foot and ankle. Amsterdam: Elsevier; 2006. 492-568.

17. Miller TT. Painful accessory bones of the foot. Semin Musculoskelet Radiol. 2002;6(2):153-61.

18. Keats TE. The foot. In: Keats TE, Anderson MW, eds. Atlas of normal roentgen variants that may simulate disease. St. Louis: Mosby-Year Book; 1992. 637-53.

19. Tsuruta T, Shiokawa Y, Kato A, et al. Radiological study of the accessory skeletal elements in the foot and ankle (author's transl). Nihon Seikeigeka Gakkai Zasshi. 1981;55(4):357-70.

20. Sobel M, Pavlov H, Geppert MJ, Thompson FM, DiCarlo EF, Davis WH. Painful os peroneum syndrome: a spectrum of conditions responsible for plantar lateral foot pain. Foot Ankle Int. 1994;15(3):112-24.

21. Miller TT, Staron RB, Feldman F, Parisien M, Glucksman WJ, Gandolfo LH. The symptomatic accessory tarsal navicular bone: assessment with MR imaging. Radiology. 1995;195(3):849-53. 
Lee et al. Accessory Bones and Tarsal Coalitions in Radiographic Findings

Clinics in Orthopedic Surgery • Vol. 12, No. 2, $2020 \bullet$ www.ecios.org

22. Lawson JP. International Skeletal Society Lecture in honor of Howard D. Dorfman. Clinically significant radiologic anatomic variants of the skeleton. AJR Am J Roentgenol. 1994;163(2):249-55.

23. Lee DY, Lee DJ, Kim DH, Shin HS, Jung WI. Posttraumatic subfibular ossicle formation in children: experience in a single primary care unit. J Pediatr Orthop. 2018;38(9):e5305.

24. Berg EE. The symptomatic os subfibulare: avulsion fracture of the fibula associated with recurrent instability of the ankle. J Bone Joint Surg Am. 1991;73(8):1251-4.

25. Lysack JT, Fenton PV. Variations in calcaneonavicular morphology demonstrated with radiography. Radiology. 2004;230(2):493-7.
26. Solomon LB, Ruhli FJ, Taylor J, Ferris L, Pope R, Henneberg M. A dissection and computer tomograph study of tarsal coalitions in 100 cadaver feet. J Orthop Res. 2003;21(2):3528 .

27. Nalaboff KM, Schweitzer ME. MRI of tarsal coalition: frequency, distribution, and innovative signs. Bull NYU Hosp Jt Dis. 2008;66(1):14-21.

28. Thompson FM, Chang VK. The two-boned fifth toe: clinical implications. Foot Ankle Int. 1995;16(1):34-6.

29. Nakashima T, Hojo T, Suzuki K, Ijichi M. Symphalangism (two phalanges) in the digits of the Japanese foot. Ann Anat. 1995;177(3):275-8. 